\title{
Influence of Infusion of Different Liquid on Changes of Blood Gas and Electrolyte of Children during the Perioperative Period
}

\author{
Shuang Qi, Fanglei Han and Feng Liang ${ }^{a}$ \\ China-Japan Union Hospital of Jilin University
}

\begin{abstract}
Objective To compare the effects of sodium potassium magnesium calcium and Glucose Injection, 5\% Glucose Injection and 9\% Sodium Chloride Injection on children with blood glucose, blood lactic acid and blood gas electrolyte during operation on children. Methods patients were randomly divided into A group(sodium potassium magnesium calcium and Glucose Injection group, $\mathrm{n}=20)$, B group $(5 \%$ sodium chloride glucose injection, $\mathrm{n}=20$ )and $\mathrm{C}$ group $(9 \%$ Sodium Chloride Injection group, $\mathrm{n}=20)$. Blood glucose ,blood lactic acid, arterial blood Gas and electrolytes were measured and compared before infusion (T0)and on postoperative time(T1). Results blood glucose in B group increased but decreased significantly in $\mathrm{C}$ group $(\mathrm{P}<0.05)$.; Blood lactic acid in $\mathrm{C}$ group significantly decreased than the other two groups $(\mathrm{P}<0.05) ; \mathrm{Mg} 2+$ decreased in $\mathrm{B}$ and $\mathrm{C}$ groups $(\mathrm{P}<0.05)$. Conclusion Sodium Potassium Magnesium Calcium and Glucose Injection has the same efficacy and safety as commonly used $5 \%$ sodium chloride glucose injection and $9 \%$ sodium chloride injection, when infused in pediatric patients during perioperative period.
\end{abstract}

\section{Instruction}

The focus of fluid management of children is the maintenance of environment stabilization during the perioperative period. Because children have their unique characteristics in terms of the dissection and physiology compared with those of adults, there have long been controversies in terms of the selection of transfusion liquid during the perioperative period ${ }^{[1]}$. Sodium Potassium Magnesium Calcium and Glucose Injection (Lejay) is a kind of compound sodium acetate electrolyte solution containing a variety of ingredients, such as sodium, potassium, magnesium, calcium, chlorine and glucose (1\%). Its composition is quite similar to extracellular fluid of human body and it is widely used for adults' water complement and the maintenance of electrolyte balance of the body in clinical practice. However, few studies have focused on its effectiveness and security when it is used to children.

This study aims to study the influence of Sodium Potassium Magnesium Calcium and Glucose Injection on changes of blood glucose, blood lactic acid and blood gas and electrolyte of children during the perioperative period so as to provide theoretical basis for its clinical application to children.

\section{Materials and Methods}

\footnotetext{
a Corresponding author: 295253720@qq.com
} 


\subsection{Generally}

Generally speaking, the materials shall be approved by Ethics Committee of our hospital. In addition, our hospital shall sign the informed consent form with family members of children patients. Selective operations for 60 cases of children patients (male or female) aged between 1 and 5 years old were done from January, 2014 to June, 2014 in China-Japan Union Hospital of Jilin University. Their body weight shall be between $8 \mathrm{~kg}$ and $20 \mathrm{~kg}$ and their ASA shall belong to level I $\sim$ II . These children shall have no heart, lung, liver, kidney diseases and endocrine diseases before the operation. The operation was arranged between 8:30 a.m. and 9:00 a.m. and it shall not last for more than two hours. In addition, there shall be lower blood loss. The children were randomly divided into three groups: the group of Sodium Potassium Magnesium Calcium and Glucose Injection (Group A), the group of 5\% dextrose injection (Group B) and the group of 9\% parenteral solution (Group C). Each group includes 20 cases.

\subsection{Anesthesia method}

Abrosia time of children patients: They were forbidden to drink clear drinks within two hours before the anesthesia, breast milk within four hours before the anesthesia and milk or food within six hours before the anesthesia. Thirty minutes before the operation, they were injected with the atropine of $0.015 \mathrm{mg} / \mathrm{kg}$. Besides, two hours before the anesthetization, venous channels were opened in the sickroom. Children patients of Group A were injected with Sodium Potassium Magnesium Calcium and Glucose Injection (Jiangsu Hengrui Medicine co.,LTD, Lejay, State Medical Approval Number: H20051995), those of Group B were injected with 5\% dextrose injection (Sichuan Kolun Pharmaceutical Co., LTD; State Medical Approval Number: H51020636) and those of Group C were injected with 9\% sodium chloride injection (Sichuan Kolun Pharmaceutical Co., LTD; State Medical Approval Number: H51021158). The liquid infusion quantity can be seen in Table 1. Penehyclidine hydrochloride of $0.01 \mathrm{mg} / \mathrm{kg}$ was injected to the muscles within 30 minutes before the operation. Midazolam of $0.05 \sim 0.1 \mathrm{mg} / \mathrm{kg}$, propofol of $1.5 \sim 2 \mathrm{mg} / \mathrm{kg}$, vecuronium bromide of $0.05 \sim 0.1 \mathrm{mg} / \mathrm{kg}$ and sufentanil of $0.05 \mu \mathrm{g} / \mathrm{kg}$ were injected through the way of anesthesia induction and intravenous injection. Besides, the concentration of sevoflurane was adjusted to be between $2.5 \%$ and $5.0 \%$ during the operation so as to maintain the anesthetization effect.

\subsection{Monitoring index}

$\mathrm{BP}, \mathrm{HR}, \mathrm{SpO}_{2}$ and $\mathrm{PaCO}_{2}$ of children patients were monitored routinely in the operation. Invasive arterial blood with the total amount of $2 \mathrm{ml}$ was drawn from three groups of children patients at the starting point of the transfusion $\left(\mathrm{T}_{0}\right)$ and the ending time of the operation $\left(\mathrm{T}_{1}\right)$ respectively. Then, the blood-gas analyzer (i-STAT 200 of ABBOTT Company of USA) was used to detect the electrolyte $\left(\mathrm{Na}^{+}, \mathrm{K}^{+}, \mathrm{Ca}^{2+}\right.$ and $\left.\mathrm{Mg}^{2+}\right)$, the buffuer excess (BE), $\mathrm{PCO}_{2}, \mathrm{HCO}_{3}{ }^{-}, \mathrm{PH}$ value, blood glucose, lactic acid concentration and other indexes. In addition, the results, operation time and adverse events were recorded.

\subsection{Analyze data}

The statistical software SPSS 13.0 was used to count and analyze data. Besides, SPSS 11.0 software was also used and $\chi^{2}$ test was adopted to show the counting data of the observed data while mean \pm standard deviation $\left(\bar{X}_{ \pm S}\right)$ was used to display the measurement data. Intra-group comparison was also conducted for pairing t-testing and inter-group comparison was analyzed by the one-way variance. $\mathrm{P}$ $<0.05$ means that there is a significant difference. 
Table 1. Supplement of demand quantity of liquid during the operation

\begin{tabular}{ccc}
\hline $\begin{array}{c}\text { Maintaining dosage } \\
\text { per hour (EFR) }\end{array}$ & $\begin{array}{r}0 \sim 10 \mathrm{~kg} \\
10 \sim 20 \mathrm{~kg} \\
>20 \mathrm{~kg}\end{array}$ & $\begin{array}{c}4 \mathrm{ml} / \mathrm{kg} / \mathrm{h} \\
2 \mathrm{ml} / \mathrm{kg} / \mathrm{h} \\
1 \mathrm{ml} / \mathrm{kg} / \mathrm{h}\end{array}$ \\
\hline $\begin{array}{c}\text { Estimate the amount } \\
\text { of fluid loss before } \\
\text { the pre-operation } \\
\text { (EFD) }\end{array}$ & $\begin{array}{c}\text { Inject } 1 / 2 \mathrm{EFD}+\mathrm{EFR} \text { in the first hour } \\
\text { Inject } 1 / 4 \mathrm{EFD}+\mathrm{EFR} \text { in the second } \\
\text { hour }\end{array}$ \\
\hline $\begin{array}{c}\text { Inapparent loss } \\
\text { amount (IL) }\end{array}$ & $1 \mathrm{ml} / \mathrm{kg} / \mathrm{h}$ \\
\hline $\begin{array}{c}\text { The total transfusion } \\
\text { amount during the } \\
\text { operation }\end{array}$ & EFR $+\mathrm{EFD}+\mathrm{IL}$ \\
\hline
\end{tabular}

\section{Results}

\subsection{Children patients}

Children patients of the three groups have no significant difference $(\mathrm{P}>0.05$. refer to Table 2$)$ in terms of their age, sex ratio, body weight and operation time. Table 2 The comparison of the general information of three groups of children patients $(n=20)$

\subsection{Intra-group}

Comparison and inter-group comparison of them show that they have no significant difference $(\mathrm{P}>0.05$; Table 2) in terms of $\mathrm{PH}, \mathrm{PCO}_{2}, \mathrm{HCO}_{3}{ }^{-}$of the blood and $\mathrm{BE}$ value.

Table 2. Comparison of blood gas indexes of three groups of children patients $(\bar{X} \pm S$, n=20)

\begin{tabular}{llclcl}
\hline Group & $\begin{array}{c}\text { Number } \\
\text { of cases }\end{array}$ & $\begin{array}{c}\text { Age } \\
\text { (Years } \\
\text { old) }\end{array}$ & $\begin{array}{c}\text { Male / } \\
\text { female }\end{array}$ & $\begin{array}{c}\text { Body } \\
\text { weight } \\
(\mathrm{kg})\end{array}$ & $\begin{array}{l}\text { Operation time } \\
(\mathrm{min})\end{array}$ \\
\hline Group A & 20 & $3.7 \pm 1.3$ & $11 / 9$ & $13.5 \pm 5.4$ & $111 \pm 10.8$ \\
Group B & 20 & $3.9 \pm 1.1$ & $13 / 7$ & $13.7 \pm 5.1$ & $110 \pm 10.6$ \\
Group C & 20 & $3.8 \pm 1.2$ & $12 / 8$ & $13.8 \pm 5.3$ & $112 \pm 11.1$ \\
\hline
\end{tabular}

\subsection{Blood glucose}

Blood glucose concentration of children patients of the three groups showed no significant difference $(\mathrm{P}>0.05)$ at the starting point of the transfusion $\left(\mathrm{T}_{0}\right)$. However, at the ending point of the operation $\left(\mathrm{T}_{1}\right)$, the blood glucose of Group $\mathrm{A}$ and Group $\mathrm{B}$ was all higher than $\mathrm{T}_{0}$. The blood glucose concentration of Group B showed significant difference $(\mathrm{P}<0.05)$ compared with that before the transfusion and that index of Group $\mathrm{C}$ was lower than $\mathrm{T}_{0}$, which displayed a significant difference $(\mathrm{P}$ $<0.05)$ compared with that before the transfusion. Although the blood glucose concentration of Group A was higher than that before the transfusion, it showed no significant difference $(\mathrm{P}>0.05)$. The inter-group comparison of the three groups in terms of the blood glucose concentration at $\mathrm{T}_{1}$ displayed significant difference $(\mathrm{P}<0.05)$, which could be seen in Table 3. 
Table 3. The comparison of the blood glucose level of three groups of children patients (mmol/1, $\bar{X} \pm S, \mathrm{n}=20$ )

\begin{tabular}{cccc}
\hline & Group A & Group B & Group C \\
Group/Time & & & \\
\hline $\mathrm{T}_{0}$ & $4.74 \pm 0.73$ & $4.81 \pm 0.82$ & $4.95 \pm 0.79$ \\
$\mathrm{~T}_{1}$ & $4.98 \pm 0.68^{\#}$ & $6.32 \pm 1.08^{* \#}$ & $3.82 \pm 0.53^{\triangle \#}$ \\
\hline
\end{tabular}

\subsection{Lactic acid}

The blood lactic acid concentration of children patients of the three groups showed no significant difference $(\mathrm{P}>0.05)$ at the starting point of the transfusion $\left(\mathrm{T}_{0}\right)$. However, at the ending point of the operation $\left(\mathrm{T}_{1}\right)$, the blood lactic acid concentration of Group A and Group B was all higher than $\mathrm{T}_{0}$ but they showed no significant difference $(\mathrm{P}>0.05)$. The concentration value of blood lactic acid of Group $C$ at $T_{1}$ decreased significantly (which was lower than the baseline value $T_{0}(P<0.05)$ ) compared with that of the other two groups, which could be seen in Table 4.

Table 4. The comparison of the blood lactic acid level of three groups of children patients $(\mathrm{mmol} / \mathrm{l}$,

$$
\bar{X} \pm S_{, \mathrm{n}=20)}
$$

\begin{tabular}{llll}
\hline $\begin{array}{l}\text { Group/ } \\
\text { Time }\end{array}$ & Group A & Group B & Group C \\
\hline $\mathrm{T}_{0}$ & $1.21 \pm 0.43$ & $1.18 \pm 0.54$ & $1.22 \pm 0.46$ \\
$\mathrm{~T}_{1}$ & $1.25 \pm 0.63$ & $1.23 \pm 0.39$ & $1.02 \pm 0.37 *^{*}$ \\
\hline
\end{tabular}

At $\mathrm{T}_{1}$ : Compared with the figure before the transfusion, the blood lactic acid level of Group C: $\mathrm{P}^{*}<0.05$; the comparison between Group C and Group A and $\mathrm{B}$ at $\mathrm{T}_{1} \mathrm{P}^{\#}<0.05$.

\subsection{Electrolyte}

$\mathrm{Na}^{+}, \mathrm{K}^{+}, \mathrm{Ca}^{2+}$ and $\mathrm{Mg}^{2+}$ concentration of children patients of the three groups showed no significant difference $(\mathrm{P}>0.05)$ at the starting point of the transfusion $\left(\mathrm{T}_{0}\right)$. The intra-group and inter-group comparison showed that $\mathrm{Na}^{+}, \mathrm{K}^{+}$and $\mathrm{Ca}^{2+}$ concentration levels of the three groups all dropped at $\mathrm{T}_{1}$ compared with that at $\mathrm{T}_{0}$, but they showed no significant difference $(\mathrm{P}>0.05)$. The $\mathrm{Mg}^{2+}$ concentration level of three groups all dropped at $\mathrm{T}_{1}$ compared with that at $\mathrm{T}_{0} \quad(\mathrm{P}<0.05)$ and Group $\mathrm{B}$ and Group $\mathrm{C}$ had a more obvious decline at $\mathrm{T}_{1}$ compared with that of Group A. The difference had statistical significance $(\mathrm{P}<0.05)$, which could be seen in Table 5 .

Table 5. The comparison of the blood electrolyte concentration value of three groups of children patients (mmol/1,

$$
\bar{X} \pm S, \mathrm{n}=20)
$$

\begin{tabular}{clcccl}
\hline Group & $\mathrm{Time}$ & $\mathrm{Na}+$ & $\mathrm{K}+$ & $\mathrm{Ca} 2+$ & $\mathrm{Mg}^{2+}$ \\
\hline Group A & $\mathrm{T}_{0}$ & $143.44 \pm 5.75$ & $3.91 \pm 0.39$ & $1.31 \pm 0.21$ & $1.08 \pm 0.05$ \\
& $\mathrm{~T}_{1}$ & $141.64 \pm 4.92$ & $3.80 \pm 0.50$ & $1.28 \pm 0.22$ & $1.01 \pm 0.03$ \\
Group B & $\mathrm{T}_{0}$ & $142.61 \pm 5.87$ & $3.88 \pm 0.34$ & $1.30 \pm 0.19$ & $1.06 \pm 0.08$ \\
& $\mathrm{~T}_{1}$ & $139.44 \pm 4.32$ & $3.72 \pm 0.48$ & $1.25 \pm 0.23$ & $0.80 \pm 0.03^{* \#}$ \\
Group C & $\mathrm{T}_{0}$ & $141.56 \pm 5.63$ & $3.85 \pm 0.33$ & $1.32 \pm 0.24$ & $1.03 \pm 0.05$ \\
& $\mathrm{~T}_{1}$ & $140.27 \pm 5.28$ & $3.79 \pm 0.27$ & $1.27 \pm 0.26$ & $0.86 \pm 0.05^{* \#}$ \\
\hline
\end{tabular}

$\mathrm{Mg}^{2+}$ concentration of Group $\mathrm{B}$ and Group $\mathrm{C}$ compared with that before the infusion $\mathrm{P}^{*}<0.05$; the comparison between Group B, C and Group A: $\mathrm{P}^{\#}<0.0$ 


\section{Discussion}

People often hold the old concept that children have a relatively high basal metabolic rate and they mainly rely on glucose for their supply of energy. Thus, glucose liquid must be injected during the perioperative period regularly ${ }^{[2]}$. However, with the extension of the glucose liquid infusion time, the blood glucose concentration of children patients in Group B increases continually and there are even three cases reaching the critical value. This reminds us that the supply of glucose to children shall be handled with care and the continuous infusion of $5 \%$ glucose liquid to children during the perioperative period may cause the risk of hyperglycemia. Lactic acid, which is the substrate in the gluconeogenesis process, can partly replace some glucose to maintain the energy supply of the body in case of the short supply of glucose ${ }^{[3]}$. In this experiment, sugar solution was not injected to children of Group C. After the operation, their blood glucose level dropped but is still within the normal range. However, the lactic acid concentration of children patients is significantly lower than that of the other two groups, showing that the reason why children patients with the only infusion of sugar-free $9 \%$ sodium chloride injection have no risks of hypoglycemia during the perioperative period is more likely to be caused by more may be caused by irritable glycometabolism disorder ${ }^{[4]}$ caused by anesthesia and surgical stimulation. The reduction of blood lactic acid concentration indicates that the glucose reserve in their bodies has been gradually depleted and the gluconeogenesis course has been triggered. This cannot meet energy demands of children.

$\mathrm{Na}^{+}$and $\mathrm{K}^{+}$, which can maintain the normal metabolism of cells, are the most important electrolytes in the cell. $\mathrm{Ca}^{2+}$ in the blood can maintain the stabilization of nerves and muscles. The content of $\mathrm{Mg}^{2+}$ in the cell, which ranks the second, is only lower than that of $\mathrm{K}^{+}$and it plays an important role as the membrane stabilizer of cytomembrane and cytoplasm organelle ${ }^{[5]}$. In addition, studies have shown that $\mathrm{Mg}^{2+}$ is also related to the metabolism of carbohydrate and the change of its concentration can affect the steady state of the glucose and even cause the abnormal glucose metabolism ${ }^{[6]}$.

Besides, Lejay adopts sodium acetate as the buffering substance. The bicarbonate radical of acetate in internal metabolism have the buffering capacity and it can be eventually transformed into carbon dioxide and water, which can reduce the metabolic burden of the liver ${ }^{[7]}$. It is the only extracellular fluid replenishing liquor which has the same $\mathrm{PH}$ value with that of the blood plasma at present. Thus, it can have a physiological advantage than 5\% dextrose injection and 9\% sodium chloride solution if it is used to the infusion of children during the perioperative period.

In conclusion, Sodium Potassium Magnesium Calcium and Glucose Injection (Lejay) is a kind of safe, effective and ideal intravenous infusion to children during the perioperative period and it is worth to be popularized and applied to clinic practices.

\section{References}

1. Xinliang Zuo, Yinming Zeng, Boluan Chen, Editor. Modern Anesthesiology [M]. Third Edition. Beijing: People's Medical Publishing House, 2003,1431 1432. (In Chinese)

2. Nakaimura $\mathrm{K}$ et al. Special pediatric problems in fluid and electrolyte therapy in surgery [J].Anesthesioloy, 1990, 72:1005.

3. Airu Zhou, Xiliang Cha, Editor. Biochemistry [M]. Fifth Edition. Beijing: People's Medical Publishing House, 2000,129. (In Chinese)

4. Korusi Ca, HauptmanA, BrundulaA, et al. Perioperative management with glucose solution and insulin[J].Coll antropol ,2009,33(2):653 657.

5. Dube L, Granry JC. The therapeutic use of magnesium in anesthesiology, intensive care and emergency medicine:a review[J].Can J Anaesth,2003,50(7):732 746.

6. Musso CG, Magnesium metabolism in health and disease [J].Int Urol Nephrol, 2009, 41(2):357 362.

7. Boluan Chen. Editor, Clinical Anesthesiology and Pharmacology [M]. First Edition. Beijing: People's Medical Publishing House, 2000, 50 584. (In Chinese) 